\title{
The impact assessment of environmental factors on ascariasis incidence
}

\author{
Anton Martsev, ${ }^{1, *}$ \\ ${ }^{1}$ Vladimir State University named after A.G. and N.G. Stoletovs', Gorky Street 87, 600000, Vladimir, \\ Russia
}

\begin{abstract}
In order to make effective managerial decisions regarding sanitary-epidemiological and preventive measures, the environmental factors potentially affecting the ascariasis epidemic process in the Vladimir region (Russia) have been searched. The archived statistics on ascariasis incidence among the population has been analyzed concerning the state of the environment, socio-economic situation, as well as climate indicators in region. Statistical data processing and correlation and regression analysis have been performed using the STATISTICA software. The maps have been compiled and edited using ArcView 3.1 GIS and standard Paint computer programs. The study showed that climatic environmental parameters determining the possibility of ascaris developing eggs in the environment reaching the infective stage retain the leading role in ascariasis epidemiology in the Vladimir region. The regional factor influencing the epidemic process is air pollution from stationary objects. The mathematical equation was made to forecast the morbidity level in the region. The obtained data can be used for risk assessment of ascariasis infection in order to ensure biological safety in the region.
\end{abstract}

\section{Introduction.}

Parasitic diseases cause the delay in children mental and physical development, as well as workability decrease of the adult population, so preventing their spread is a very urgent task all over the world.

Under the conditions of environment anthropogenic transformation, traditional methods and approaches for monitoring parasitic diseases become insufficient. Therefore, currently the geographical and ecological directions are to be studied for the research of parasitic diseases to forecast and prevent their spread. [1]. Different incidence rates of epidemic process in different regions depende on a number of climatic, environmental, social and economic factors $[2 ; 3]$. In this regard, the principle task of sanitary parasitology nowadays is to establish patterns of parasitosis pathogens distribution in the environment, to determine their role in the epidemiology of this pathogens group. Mathematic-statistical methods and geographic geo-informational systems (GIS) are proposed to be used for the forecast measures allowing to apply multi-factor analysis of various data and to identify the areas favorable for parasitosis spread of in the visualized form $[4 ; 5 ; 6]$.

\footnotetext{
* Corresponding author: martsevaa@yandex.ru
} 
One of the most common parasitic diseases in the world is ascariasis, which annually infects about 1.5 million people, according to the expert data. In Russia from 40 to 60 thousand cases of this nosology are annually registered [7]. The effective managerial decisions concerning sanitary-epidemiological and preventive measures depend among the other on the regional characteristics, so the research objective was to search for environmental factors potentially affecting the ascariasis epidemic process in the Central part of the Russian Federation. This study embraces environmental factors on the ascariasis incidence among the population of the Vladimir region, Russia.

\section{Materials and methods}

\subsection{Study area}

The Vladimir region is located in the center of the European part of Russia in the Southern Volga-Oka interfluve. It borders the Moscow region in the West and southwest, Yaroslavl and Ivanovo in the North, Ryazan in the South, and Nizhny Novgorod in the East. The region covers an area between $56^{\circ} 47^{\prime}$ and $55^{\circ} 09^{\prime}$ North latitude and $38^{\circ} 17^{\prime}$ and $42^{\circ} 58^{\prime}$ East longitude (figure 1). The area is $29,000 \mathrm{~km}^{2}$, stretching for $170 \mathrm{~km}$ from North to South and $280 \mathrm{~km}$ from West to East.

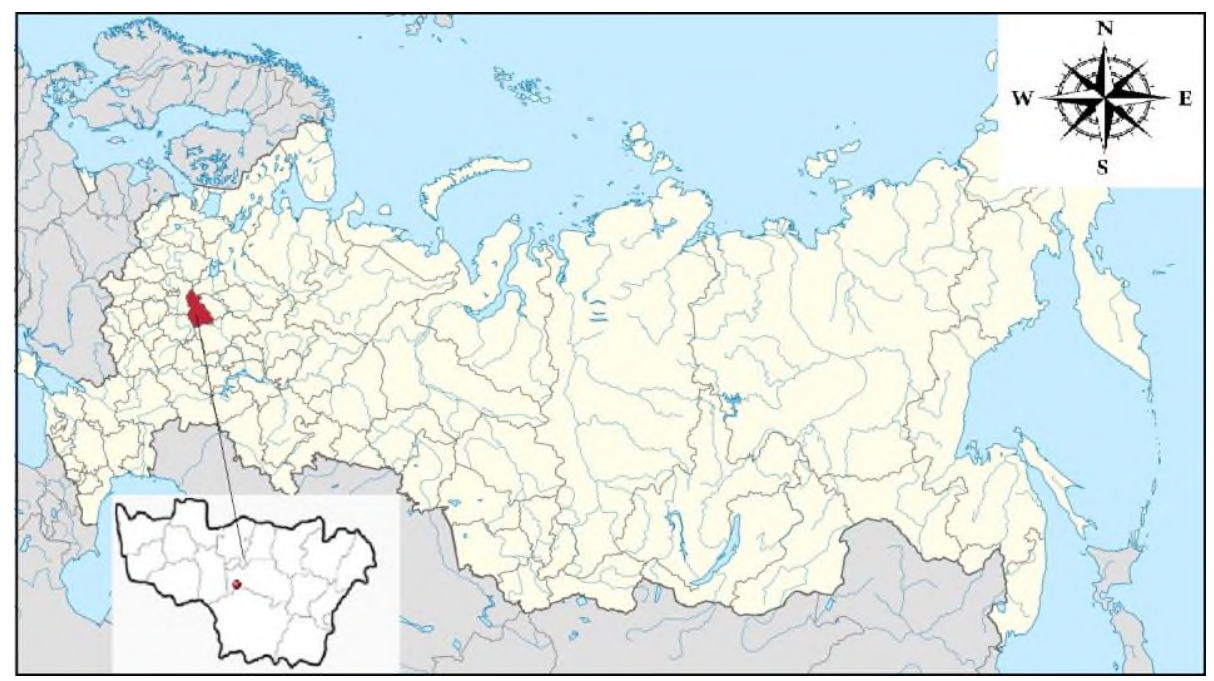

Fig. 1. Location of the study area.

The climate in the region is moderately continental, with warm summers, moderately cold winters and pronounced transitional seasons. The period of the average temperature below $0{ }^{\circ} \mathrm{C}$ lasts 75 days. The average annual temperature is $15{ }^{\circ} \mathrm{C}$ (standard deviation 12 ${ }^{\circ} \mathrm{C}$ ), average January temperature is from $-11{ }^{\circ} \mathrm{C}$ in the North-West region to $-12{ }^{\circ} \mathrm{C}$ in the South-East. In July it is about $+18{ }^{\circ} \mathrm{C}$. The average annual precipitation amounts 550-600 $\mathrm{mm}$, with maximum precipitation in summer. In winter the stable snow cover is formed up to $55 \mathrm{~cm}$ thick by the end of February (it lies on average for 144 days).

According to Rosstat the population of the region is 1358416 people (2020). The population density is 46.71 people $/ \mathrm{km}^{2}$ (2020). Urban population amounts $78,24 \%$ (2020).

\subsection{Statistics}


The archival statistics was analyzed in the course of the study concerning:

- the ascariasis incidence - from the record form №2 "Records on infectious and parasitic diseases" issued by the Vladimir region Hygiene and Epidemiology Center of Rospotrebnadzor Department for the period of 2000 - 2016;

- environment condition (air, water and soil pollution) from the Regional Administration Reports "On the state of environment and population's health Vladimir region";

- $\quad$ socio-economic situation (unemployment rate, average salary, number of doctors and nurses, housing availability) - from the statistical annual reports of the Regional Federal state statistics service for the Vladimir region;

- climate indicators (average monthly temperature, number of days in a month with precipitation, humidity and snow cover) - from the portal www.atlas-yakutia.ru.

\subsection{Statistical analysis}

To determine the statistically significant factors related to the incidence rate $(p \leq 0.05)$, we used the method of correlation and regression analysis with the calculation of the Pearson pair correlation coefficient. Such factors identification is appropriate, even if casual effect cannot be reliably interpreted at the moment. The ignorance of the individual indicators role in shaping the studied process dynamics in the presence of a significant correlation should not become the reason for excluding the indicators from the forecast equations. The probable climate indicators influence on the morbidity level during both current and previous year (i.e., with a shift in climate indicators for the year ahead relative to the value of morbidity) have been considered for calculating the correlation coefficient. Multiple nonlinear regression has been applied for determining the most significant factors by stepby-step inclusion and the forecast equation has been made, which significance was determined by $\mathrm{R}^{2}$ value and residues distribution. To define the possible influence of soil types in the region on ascariasis incidence, Spearman's rank correlation coefficient was determined. Statistics processing, correlation and regression analysis were performed using the STATISTICA program. The maps compilation and edition were made using ArcView 3.1 GIS program and the standard Paint computer program.

\section{Results and discussion}

\subsection{Analysis of ascariasis incidence among population}

The downward trend of the ascariasis incidence in the region is observed. The incidence rate in 2016 was detected as 21.3 per 100 thousand people against 74 per 100 thousand in 2000 (figure 2).

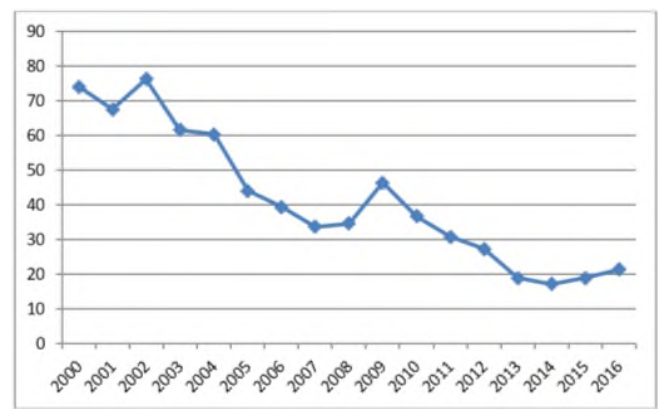


Fig. 2. Ascariasis incidence dynamics in the Vladimir region.

About $90 \%$ of all incidence are children under 17 years old. The proportion of schoolchildren among children with ascariasis is about $35 \%$ on average, children not attending preschool organizations $-28 \%$, children of preschool organizations $-34 \%$ [8].

The distribution of ascariasis incidence in the region is uneven. The most unfavorable situation is observed in Gorokhovets district, where the incidence rate exceeds the regional average by almost 9.5 times.

\subsection{State of the environment in the Vladimir region}

According to numerous data from hygiene scientists, air pollution is one of the priority risk factors in the development of various human nosologies. According to Administration annual reports the Vladimir region remains a region of fairly high industrial potential. Among the industries polluting the environment more than others are enterprises of heat and power engineering, mechanical engineering and metalworking, construction materials production (including glass works), housing and communal services, non-manufacturing industries, transport and communications.

The amount of pollutants emissions from stationary sources in the region during the analyzed period decreased by $41 \%$ (from 53.3 thousand tons in 2001 to 33.5 thousand tons in 2015). It depends on drop in the industrial production level. But about $23 \%$ of all emissions from stationary sources are in regional center. It should be noted that alongside the population welfare increase the number of vehicles in the region is increasing thus causing the increase of pollutants emissions into the air. If in 2001 their share amounted $53.7 \%$ (61.977 thousand tons) of the emissions total amount, in 2015 it was $80.8 \%$ (141.4 thousand tons). The main pollutants entering the air in the course vehicles operation are: $\mathrm{CO}, \mathrm{NO} 2$, hydrocarbons, soot, $\mathrm{SO} 2$, etc.

One of the risk factors of human infection with Ascaris is likely to be caused by drinking water parasitic contamination. In the Vladimir region the water is supplied from two types of sources: surface water and underground water. Basically the underground aquifers are used as centralized water supply sources, but $20 \%$ of the regional population uses water from surface sources, which in most cases do not meet the hygienic standards for microbiological indicators. Industrial enterprises, housing and communal facilities, and kettle breeding complexes remain the main pollution sources of open water bodies in places where the population uses water. The percentage of non-standard samples regarding microbiological indicators in surface water sources stays at high level - 89.4\%, which depends on high anthropogenic load. Despite water treatment facilities and water purification plants in the region (many of which require modernizing), as a part of the intestinal diseases prevention, it is mandatory for the population to boil tap water before using it.

One of the risk factors of human infection with Ascaris may be parasitic contamination of drinking water. There are two types of water use sources in the Vladimir region: surface water and underground water. Underground aquifers are mainly used as sources of centralized water supply, but $20 \%$ of the region's population uses water from surface sources, the main share of which does not meet the hygienic standards for microbiological indicators. From all environment objects the soil is most intensively affected by Ascaris eggs, and the epidemic situation primarily depends on the sanitary condition of the area and fruit and vegetables contamination by helminth eggs. The population is infected primarily through eating contaminated with helminths eggs berries, vegetables and greenery. An additional infection factor might be imported food from other regions, but the role of local food is undoubtedly more significant, since it is available throughout the year. The analysis of parasitological soil contamination in the region is carried out by specialists of Hygiene 
and Epidemiology Center, but this research data is not enough to comprehend the complete contamination picture of the residential areas in the region.

\subsection{Coupled mathematical analysis of ascariasis incidence and environmental factors}

Ascariasis is a disease caused by parasitising of the roundworm Ascaris lumbricoides in the human intestine. This species belongs to the group of the so-called geohelminths, the fertilized eggs development into the stage of invasive larvae occurs in the external environment and without the participation of an intermediate host. Since this species is dioecious, for the ascariasis epidemic process onset the human being is required to be infected by 2 different sex species at the same time. Moreover, certain favorable environmental conditions are known to be required for the development of fertilized eggs into the invasive larva stage. Primarily it applies to the climate indicators (temperature and humidity) [9].

It is known that the very possibility of the larva development into the invasive stage and its duration depends on the accumulation time of a certain amount of heat, the so-called sum of Gadus-days, which is calculated according to the effective temperatures [5]. Up to now several methods based on climatic indicators are used to identify the areas potentially endemic regarding ascariasis (i.e. according to Ascaris eggs survival and development). The Vladimir region is characterized by natural and climatic indicators favorable for this disease nidus, which is confirmed by statistics of Hygiene and Epidemiology Center of Federal Biomedical Agency of Russia.

Since the climate indicators directly affect the time of ascaris larva development and survival in the external environment, we analyzed their possible influence on the incidence of ascariasis in dynamics. The correlation analysis resulted in statistically significant dependence found between morbidity and the following indicators from other numerous indices: the average monthly temperature in previous year May $(r=-0.65 \mathrm{p}=0.017)$, precipitation in June $(r=0.75 \mathrm{p}=0.003)$, rainfall in previous year June $(r=0.68 \mathrm{p}=0.011)$, snow cover in January $(r=0,87 p=0,000)$, snow cover in previous year January $(r=0,65 p$ $=0.016)$ and snow cover in previous year February $(r=0,58 \mathrm{p}=0.04)$.

Our results obtained during the correlation and regression analysis (regarding climate parameters) conform the published data of the Russian scientists [9]. It is known that beside the temperature environment humidity greatly affects Ascaris eggs development. Thus, the highest rate of eggs development is observed under the highest soil humidity, but when it decreases up to $8 \%$ their development stops. In this regard, it seems very appropriate to have positive correlations between the incidence and precipitation in June. Herewith the precipitation can contribute not only to the soil moistening and thus accelerating the eggs development, but also serve as a factor in washing out mature eggs from the soil, contributing to the food contamination. Positive correlations of the incidence and snow cover can be explained by the presence of a more comfortable temperature regime in this case for the eggs preservation in the environment in winter period. Immature Ascaris lumbricoides eggs are known to be more resistant to low temperatures than mature ones, but even they at temperatures below $-12^{\circ} \mathrm{C}$ during 3 months slow down their development rate. Mature eggs under such conditions completely die [5]. Due to the significant changes in the temperature regime in recent years namely warming in winter, we should expect more invasive Ascaris lumbricoides eggs in the Central region environment [10].

Natural and climatic indicators, as it was noted above, determine the possibility or impossibility of Ascaris eggs development in the external environment. Basing on these indicators, we can assume the expected morbidity value in general in a particular area. It is not enough to forecast morbidity in the endemic area characterized by homogeneous natural 
and climatic indicators. Regional peculiarities (socio-economic development level and urban and rural population ratio, soil types and technogenic factors) can play the significant role in the epidemic process development. Due to the significant differentiation of morbidity indicators in the region, we searched for factors causing these differences. Romanenko N. A. and co-authors [9], as well as foreign scientists [11] indicate the influence of soil type on the Ascaris eggs development. Our analysis including the determination of Spearman rank correlation coefficient between the soil type and morbidity value in the region did not reveal statistically significant indicators.

The studies conducted in the Kursk region (Russia) [12] showed that chemical pollution of the environment leads to more intensive maturation of Ascaris eggs, making them invasive in a shorter period. But taking into account high fecundity of female Ascaris and, accordingly, egg contamination degree of environmental objects, this circumstance can cause the increase in the disease incidence. The correlation analysis result helped us to reveal that the ascariasis incidence is usually higher in those areas with highest pollutants emission into the air per inhabitant from stationary sources $(r=0.77 \mathrm{p}=0.000)$. Herewith the morbidity decrease in the region occurs against the background of industrial production decrease $(r=0.78 p=0.001)$. No correlation between the incidence values and the number of non-standard water and soil samples regarding microbiological indicators was detected.

No correlation was found between the ascariasis incidence and the level of socioeconomic development in the region, as well as the urban and rural population ratio. The conditions for the geohelminthiasis spread are believed to be more actual in rural areas [13], however, ascariasis is becoming more and more specific disease among city population. Urban population infection occurs mainly in suburban areas, and is associated with the gardens fertilization using untreated feces and sewage sludge, followed by the berries, vegetables and table greens consumption, contaminated with helminth eggs. Flies can serve as an additional factor in the spread of invasive Ascaris lumbricoides eggs.

\subsection{Epidemic process mathematical modeling}

All of the above indicators found for the correlation, were included into the regression analysis in order to create the forecast model of the epidemic process. As a result of multiple nonlinear regression analysis by step-by-step inclusion, the most significant predictors have been determined, afterwards the forecast equation was developed, which reliability was determined by $\mathrm{R}^{2}$ value of and residues distribution.

The program has determined that the most significant indicators affecting the epidemic process are emissions amount from stationary sources per person, the precipitation in previous year June, and the snow cover in current year January and previous year February.

The resulting multiple linear regression equation is as follows:

$$
\begin{gathered}
\mathrm{y}=21,522 \mathrm{X}_{1}+17,915 \mathrm{X}_{2}+4,034 \mathrm{X}_{3}+9,224 \mathrm{X}_{4}-742,077 \\
\mathrm{R}^{2}=0,99 \mathrm{p}<0,001
\end{gathered}
$$

where

$\mathrm{y}$ - population morbidity level;

$\mathrm{X} 1$ - emissions from stationary sources per person;

$\mathrm{X} 2$ - precipitation in previous year June;

$\mathrm{X} 3$ - snow cover in current year January;

$\mathrm{X} 4$ - snow cover in previous year February.

In our opinion, it is interesting to have a fairly high statistically reliable value of the correlation coefficient between the morbidity level and air pollutants amount from stationary sources per resident. This fact can be interpreted as follows. The children body is 
known to react more sensitively to chemical air pollution [14], which is manifested in the violation of the body protective functions. Besides additionally taking into account a more disdainful attitude of children to their own hygiene, we receive quite regular ratio in the children and adult incidence (9:1), as well as the incidence in relatively safe and unsafe areas in the anthropogenic aspect.

Additionally it is worth explaining the inclusion of the previous year indicators into the mathematical analysis. It was done basing on the peculiarities of the Ascaris eggs development in the environment (which can last up to several years due to the lack of necessary climatic parameters), as well as biology features in the host body. Clinical manifestations of ascariasis largely depend on the invasion intensity and parasite localization [15]. The migration phase is usually asymptomatic and parasitological diagnosis is rarely established. The symptoms of the intestinal stage are sometimes an insufficient reason to suspect infestation, and the diagnostic sign is the parasite eggs detection in the feces. However, this analysis will be negative if only males are parasitizing in the body, or if females have not yet reached fertility (it occurs on average 70-75 days after infection) or if this period is already over (usually by the 7 th month of their life). Ascaris lumbricoides life span in the host body is about one year, and the specialists do not have to determine the infection time during diagnosing.

\section{Conclusion}

The research revealed that the leading role in Ascariasis epidemic process manifestation in the Vladimir region belongs to the climatic environmental parameters determining the possibility of Ascaris eggs development in the environment up to the infective stage, and namely the precipitation in previous year June, snow cover in current year January and previous year February. Summer precipitation contributes not only to soil moisture, accelerating the Ascaris eggs development, but also is washing out factor of the mature eggs onto the soil surface and vegetable food. The snow cover provides a more comfortable temperature regime for the eggs preservation of in winter environment. A regional factor affecting the epidemic process (indirectly through the protective functions suppression of the children body and reducing the Ascaris eggs development period) is air pollution from stationary objects. The received data can be used for assessing the risk of Ascariasis infection in order to ensure biological safety of the region.

\section{References}

1. J. Gutiérrez-Jiménez Children from a rural region in the chiapas highlands, Mexico, show an increased risk of stunting and intestinal parasitoses when compared with urban children, Boletin Medico del Hospital Infantil de Mexico, 76(1), 18-26. (2019) DOI: 10.24875/BMHIM.18000069

2. S. Vaz Nery Risk factors for infection with soil-transmitted helminths during an integrated community level water, sanitation, and hygiene and deworming intervention in Timor-Leste, International Journal for Parasitology. 49(5), 389-396. (2019) DOI: 10.1016/j.ijpara.2018.12.006

3. A. J. Cooper T. Déirdre Hollingsworth The impact of seasonality on the dynamics and control of Ascaris lumbricoides infections, Journal of Theoretical Biology, 453: 96-107 (2018) DOI: 10.1016/j.jtbi.2018.05.025

4. T. A. Trifonova, A. A. Martsev Assessment and prediction of the epidemiological situation for ixodic tick-borne borreliosis in the Vladimir region, Zhurnal mikrobiologii, epidemiologii i immunobiologii, 1, 58-62. (2016) 
5. L. F. Morozova Assessment of the risk of possible local ascariasis infection on the territory of the Russian Federation (methodological principles and approaches), Meditsinskaya parazitologiya i parazitarnye bolezni. 3, 40-43 (2016)

6. S. Brooker Predicting the distribution of urinary schistosomiasis in Tanzania using satellite sensor data, Tropical Medicine and International Health, 6(12), 998-1007. (2001) DOI: 10.1046/j.1365-3156.2001.00798.x

7. V. G. Supryaga Current epidemiological situation of ascariasis in the Russian Federation, Meditsinskaya parazitologiya i parazitarnye bolezni, 1, 8-12. (2018)

8. A. A. Martsev, V. M. Rudakova Retrospective analysis of the epidemiological situation for parasitic diseases in the Vladimir region, Gigiena i sanitariya, 97( 9), 825-830. (2018) DOI: 10.18821/0016-9900-2018-97-9-825-830

9. N.A. Romanenko, I.K. Padchenko, N.V. ChebyshevSanitary Parasitology. Meditsina, $320 \mathrm{~s}(2000)$

10. A. J. Blum, P. J. Hotez Global "worming": Climate change and its projected general impact on human helminth infections, PLoS Neglected Tropical Diseases, 12(7), e0006370 (2018) DOI: 10.1371/journal.pntd.0006370

11. J. T. Anunobi Risk of soil-transmitted helminthiasis among Agrarian communities of Kogi State, Nigeria, Annals of Global Health, 85(1), 120 (2019) DOI: $10.5334 / \operatorname{aogh} .2563$

12. M. N. Tokareva Forecasting the development and survival of Ascaris eggs in the soil in the conditions of the Kursk region, Meditsinskaya parazitologiya, 2, 21-25 (2008)

13. D.Yang, Prevalence and risk factors of Ascaris lumbricoides, Trichuris trichiura and Cryptosporidium infections in elementary school children in southwestern China: A school-based cross-sectional study, International Journal of Environmental Research and Public Health, 15(9),1809. (2018) DOI: 10.3390/ijerph15091809

14. T.A. Trifonova, A.A. Martsev Assessment of the influence of atmospheric air pollution on the morbidity of the population of the Vladimir region, Gigiena i sanitariya, 94(4), 14-18 (2015)

15. V.P. Sergiev, Yu.V. Lobzin, S.S. Kozlov Parasitic diseases of man, 608 s (2011) 